\title{
Aplikasi Dynamic Factor Model untuk Nowcasting Pertumbuhan Ekonomi Regional Menggunakan Data Google Trends di Indonesia
} \author{
Trends Data in Indonesia \\ Jesica Nauli Br. Siringo Ringo ${ }^{1 *}$, Anugerah Karta Monika ${ }^{2}$ \\ 1,2 Politeknik Statistika STIS \\ Jl. Otto Iskandardinata No. 64C, Jakarta Timur 13330 \\ E-mail: 211709764@stis.ac.id
}

An Application of Dynamic Factor Model to Nowcast Regional Economic Growth Using Google

\begin{abstract}
ABSTRAK
Data mengenai aktvitas ekonomi dibutuhkan secara cepat untuk mengambil berbagai kebijakan, namun data tersebut mengalami keterlambatan publikasi, terutama pada level regional. Data Produk Domestik Regional Bruto (PDRB) dirilis dalam waktu lima minggu sejak triwulan berakhir. Upaya yang dapat dilakukan untuk menyediakan data tersebut adalah melalui nowcasting, yaitu peramalan pada periode berjalan menggunakan variabel berfrekuensi lebih tinggi. Data Google Trends merupakan data berfrekuensi tinggi yang tersedia pada waktu yang sebenarnya. Penelitian ini bertujuan untuk melakukan nowcasting pertumbuhan PDRB menggunakan data Google Trends. Metode nowcasting yang digunakan adalah Dynamic Factor Model (DFM). Hasil nowcasting menunjukkan bahwa model mampu menangkap penurunan aktivitas ekonomi sejak masa pandemi COVID-19. Hasil evaluasi pada dua rentang data menunjukkan bahwa DFM lebih baik pada rentang data yang tidak memasukkan periode adanya guncangan ekonomi.
\end{abstract}

Kata kunci: Nowcasting, Dynamic Factor Model, PDRB

\begin{abstract}
Economic activity data is urgently needed to take various policies, but the data publication is experiencing delays. Gross Domestic Regional Product (GDRP) will be released within five weeks after the quarter ends. Nowcasting is an attempt to provide this data. Nowcasting is a method of forecasting the current period using higher frequency variables. Google Trends is high frequency data that is available in real time. This study aims to nowcast GDRP growth using Google Trends data. The nowcasting method used in this study is Dynamic Factor Model (DFM). Nowcasting results show that the model is able to capture the recent downturn in economic activity since the COVID-19 pandemic. The evaluation of the models between two data ranges shows that DFM is better in the data range that does not include periods of economic shock.
\end{abstract}

Keywords: Nowcasting, Dynamic Factor Model, GDRP

\section{PENDAHULUAN}

Ketersediaan data makro ekonomi regional yang cepat memiliki keterbatasan dalam waktu pengumpulan dan pengolahannya. Data pertumbuhan ekonomi mengalami delay atau keterlambatan dalam perilisannya, selama lima minggu sejak triwulan berakhir. Kondisi tersebut terjadi pada level nasional dan regional. Upaya yang dapat dilakukan untuk pemenuhan kebutuhan data tersebut adalah melalui peramalan. Nowcasting merupakan bentuk pengembangan dari forecasting berupa peramalan pada kondisi saat ini dengan prinsip menggunakan variabel yang berfrekuensi lebih tinggi. Dalam arti, jika nowcasting dilakukan terhadap variabel triwulanan, maka variabel yang digunakan dapat berupa variabel bulanan, mingguan, atau harian.

Pada level regional, ketersediaan variabel bulanan masih sangat terbatas dibandingkan level nasional. Jumlah sampel dan sumber pengumpulan data di level regional masih sedikit. Sebagai contoh, data harga pembentuk inflasi diperoleh dari 90 kota besar di Indonesia sehingga data ini tidak representatif terhadap provinsi. Meskipun variabel bulanan pada level provinsi terbatas, namun urgensi mengenai data secara cepat sangat dibutuhkan. Selain itu, belum terdapat penelitian nowcasting pertumbuhan ekonomi maupun komponennya pada level provinsi di Indonesia. Hal ini merupakan salah satu dorongan untuk melakukan nowcasting pertumbuhan ekonomi pada level provinsi. Nowcasting pada level nasional di Indonesia sendiri sudah dilakukan oleh Tarsidin, Idham, \& Rakhman (2018), dan Luciani et al. (2018).

Akibat keterbatasan variabel, dibutuhkan sumber data yang mampu memberikan data berfrekuensi tinggi. Keberadaan data statistik resmi yang menyediakan data berfrekuensi tinggi di level regional pun masih 
terbatas. Meskipun terdapat data statistik resmi berfrekuensi tinggi seperti data finansial oleh Bank Indonesia, maupun data makroekonomi oleh Badan Pusat Statistik, namun masih terdapat keterlambatan publikasi. Data finansial yang dimaksud berupa simpanan masyarakat, pinjaman yang diberikan, dan kredit UMKM. Data makroekonomi yang disajikan oleh BPS secara bulanan, yaitu Nilai Tukar Petani (NTP), ekspor, dan impor.

Untuk mengatasi keterlambatan publikasi dari data statistik resmi, salah satu alternatif sumber data yang dapat menyajikan data pada waktu yang sangat cepat adalah Google Trends. Data mengenai banyaknya pencarian yang dilakukan oleh pengguna internet tersebut merupakan salah satu bagian dari big data. Peningkatan penggunaan internet untuk seluruh aktivitas manusia dapat memberikan gambaran mengenai aktivitas yang sedang terjadi, khususnya aktvitas ekonomi. Karakteristik dari big data yang mampu memberikan data pada waktu sebenarnya memiliki konsekuensi berupa data yang dianggap tidak representatif karena populasinya yang tidak diketahui. Hal ini menjadi salah satu pendorong pula bagi penelitian ini untuk mengetahui kebermanfaatan data Google Trends dalam meramalkan pertumbuhan ekonomi. Penelitian oleh Heikkinen (2019) menyatakan bahwa berbagai literatur ekonometrik telah menggali kemampuan data Google Trends dalam meramalkan variabel makroekonomi, seperti pengangguran, konsumsi, pertumbuhan ekonomi, penjualan mobil, bahkan data finansial.

Pandemi COVID-19 yang terjadi sejak triwulan pertama 2020 memberikan pola pergerakan yang unik pada pertumbuhan ekonomi. Terjadi penurunan pertumbuhan ekonomi secara tajam pada level nasional maupun regional. Gambar 1 menunjukkan penurunan pertumbuhan ekonomi secara tajam pada triwulan kedua 2020 di tujuh provinsi di Indonesia. Kondisi ini memerlukan perhatian, khususnya pada konteks peramalan. Adanya pergerakan pola yang sangat berbeda dibandingkan pola historisnya dapat memengaruhi peramalan yang dilakukan. Penelitian ini akan membandingkan kinerja model pada dua rentang data,yaitu dengan dan tanpa memasukan masa pandemi COVID-19.

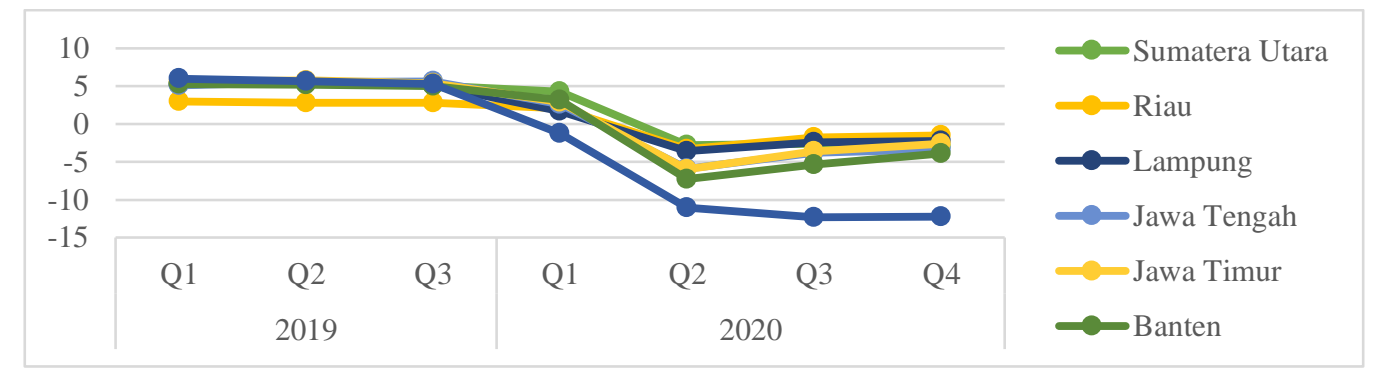

Gambar 1. Pertumbuhan PDRB tujuh provinsi pada 2019Q1-2020Q4

Nowcasting dilakukan berdasarkan fakta atau data yang tersedia, dan berfokus pada apa yang diketahui dan bisa diketahui, dan inilah dasar yang membedakannya dengan forecasting (Ineichen, 2015). Nowcasting dapat memanfaatkan model konvensional yang hanya memanfaatkan data historis dan tidak mengakomodir perbedaan frekuensi dimana hal ini serupa dengan proses dalam melakukan forecasting. Apabila proses nowcasting dilakukan dengan prinsip sebenarnya, dibutuhkan sebuah model yang mampu mengakomodir perbedaan frekuensi. Sebagai perbandingan terhadap model konvensional, penelitian oleh Giannone, Reichlin, \& Small (2008) menunjukkan bahwa DFM lebih baik dibandingkan model univariat, yaitu model random walk dan autoregressive (AR). Penelitian tersebut menunjukkan bahwa berbagai indikator dalam jumlah yang besar mampu menghasilkan peramalan ekonomi dalam jangka pendek. Kriteria pemilihan variabel dalam penelitian tersebut tidak menitikberatkan pada korelasi terhadap PDB, namun berfokus pada data berfrekuensi tinggi yang mampu memberikan informasi lebih cepat mengenai pertumbuhan ekonomi sebagai variabel referensinya.

Terdapat beberapa model ekonometrik yang dapat membentuk model nowcasting, yaitu bridge equations, Mixed Data Sampling (MIDAS), Dynamic Factor Model (DFM), dan Mixed Frequency VAR (Tarsidin, Idham, \& Rakhman, 2018). DFM merupakan metode yang mampu mengakomodir berbagai kendala pada variabel bulanan yang digunakan, seperti penggunaan himpunan data yang besar, mampu menghubungkan informasi dari variabel bulanan terhadap variabel triwulanan, dan dapat digunakan pada data dengan rentang yang tidak sama. Keberhasilannya dalam melakukan nowcasting di sejumlah negara, baik pada level nasional maupun regional, juga menjadi alasan penggunaannya dalam penelitian ini.

Penggunaan DFM untuk nowcasting diperkenalkan oleh Giannone, Reichlin, \& Small (2008) dimana estimasi DFM dilakukan melalui metode dua tahap. Sebagai pengembangan atas metode tersebut, Bańbura, Giannone, \& Reichlin (2010) membentuk DFM menggunakan algoritma ekspektasi maksimum. Pada level regional, Chernis et al. (2017) menggunakan DFM untuk nowcasting pertumbuhan ekonomi provinsi di 
Kanada, dan Clayton-Matthews \& Stock (1999) menerapkan DFM untuk membentuk indeks coincident di negara bagian Massachusetts.

Berdasarkan latar belakang dan kajian mengenai metode nowcasting yang telah dilakukan, dirumuskan tujuan penelitian yaitu pembentukan model nowcasting pertumbuhan ekonomi pada level provinsi di Indonesia menggunakan DFM. Model dibentuk menggunakan data Google Trends yang dapat diperoleh secara tepat waktu (real time). Akurasi model akan menjadi ukuran untuk mengevaluasi model yang dihasilkan dengan membandingkannya pada dua rentang data, yaitu sebelum dan masa pandemi COVID-19. Metode nowcasting yang digunakan akan dibandingkan dengan metode konvensional berupa autoregressive untuk mengetahui apakah model dengan memanfaatkan banyak variabel akan lebih bermanfaat dibandingkan model univariat.

\section{METODE}

Analisis dilakukan dengan membentuk model nowcasting menggunakan DFM dengan tahapan sebagai berikut:

1. Pemilihan variabel untuk nowcasting dengan prinsip bahwa variabel tersebut tersedia di situs web bagi seluruh pihak, mudah diakses, dan memiliki relevansi terhadap pertumbuhan ekonomi

2. Transformasi variabel untuk memenuhi kondisi stasioneritas

3. Pengujian stasioneritas menggunakan uji augmented Dickey-Fuller

4. Pembentukan model nowcasting pertumbuhan PDRB triwulanan menggunakan DFM. Hasil nowcasting akan dievaluasi berdasarkan ukuran akurasi root mean squared error (RMSE).

5. Pemeriksaan residual untuk memenuhi kondisi white noise

DFM dibangun menggunakan algoritma ekspektasi maksimum oleh Bańbura, Giannone, \& Reichlin (2010). Perbedaan waktu publikasi pada variabel bulanan menyebabkan rentang data bulanan tidak sama dimana DFM dapat mengakomodir kondisi data demikian. Algoritma ekspektasi maksimum melakukan iterasi pada estimasi dua tahap oleh Giannone, Reichlin, \& Small (2008) agar memaksimumkan fungsi likelihoodnya. Bańbura, Giannone, \& Reichlin (2010) menspesifikasikan DFM sebagai berikut:

$$
\begin{aligned}
& x_{t}=\Lambda f_{t}+\varepsilon_{t} \\
& f_{t}=A_{1} f_{t-1}+\cdots+A_{p} f_{t-p+} u_{t}, u_{t} \sim \text { i.i.d.N }\left(0, \sigma^{2}\right) \\
& \varepsilon_{i t}=\alpha_{i} \varepsilon_{i, t-1}+e_{i t}, e_{i t} \sim \text { i.i.d.N }\left(0, \sigma_{i}^{2}\right) \ldots \ldots \ldots \ldots \ldots \ldots \ldots \ldots \ldots \ldots \ldots \ldots \ldots
\end{aligned}
$$

$x_{t}=\left(x_{1 t}, x_{2 t}, \ldots, x_{n t}\right)^{\prime}$ merupakan himpunan variabel bulanan yang stasioner dan sudah distandarisasi untuk $t=1, \ldots, T$. Vektor dari faktor umum mengikuti proses VAR dengan ordo $p$ yang dinotasikan sebagai $f_{t}$. Vektor dari komponen khusus mengikuti proses AR dengan ordo $q$ yang dinotasikan sebagai $\varepsilon_{i t}$. Notasi $i$ menyatakan variabel dan $t$ menyatakan waktu dalam bulanan.

Seperti yang diketahui bahwa PDRB memiliki frekuensi triwulanan, namun variabel yang digunakan untuk membentuk faktor merupakan variabel berfrekuensi bulanan. Untuk dapat memasukkan variabel triwulanan ke dalam himpunan data bulanan, Giannone, Reichlin, \& Small (2008) dan Bańbura, Giannone, \& Reichlin (2010) mentransformasi variabel triwulanan dengan metode yang dilakukan oleh Mariano \& Murasawa (2003). Nilai PDRB dari suatu triwulan dinyatakan dalam bulan ketiga triwulan tersebut sehingga PDRB triwulanan dinotasikan sebagai $y_{t}^{Q},(t=3,6,9, \ldots)$ yaitu jumlah dari PDRB bulanan yang tidak teramati, $y_{t}^{M}$. Transformasi dari PDRB triwulanan dinyatakan oleh Mariano \& Murasawa (2003) sebagai berikut:

$$
y_{t}^{Q}=y_{t}+2 y_{t-1}+3 y_{t-2}+2 y_{t-3}+y_{t-4} \text {. }
$$

Estimasi dilakukan dengan menspesifikasikan model dalam bentuk state-space. Model yang direpresentasikan dalam bentuk state-space agar meringkas kedinamisannya (Hamilton, 1994). Bańbura, Giannone, \& Reichlin (2010) merepresentasikan model sebagai berikut :

$$
\begin{aligned}
& \bar{x}_{t}=\bar{\mu}+Z(\theta) \alpha_{t} \ldots \ldots \\
& \alpha_{t}=T(\theta) \alpha_{t-1}+\eta_{t} . .
\end{aligned}
$$

Persamaan DFM di atas diestimasi pada tahapan keempat dari proses pembentukan model nowcasting. Keseluruhan proses pembentukan DFM dilakukan menggunakan aplikasi $\mathrm{R}$ Studio dengan package nowcasting dan fungsi utama nowcast. Penjelasan mengenai package dielaskan secara rinci oleh de Valk, Mattos, Ferreira (2019).

Sebagai perbandingan antar model, ordo VAR dan jumlah faktor menggunakan nilai yang sama antar model, yaitu ordo dua $(p=2)$ dan dua faktor $(r=2)$. Pemilihan tersebut didasarkan pula atas penelitian yang dilakukan oleh Giannone, Reichlin, \& Small (2008), dan Luciani et al. (2018) sehingga ordo dan jumlah faktor diasumsikan sudah robust. Besar ordo lag yang digunakan DFM juga digunakan pada metode konvensional 
pembandingnya agar memastikan bahwa kedua model melakukan peramalan menggunakan ordo yang sama. Hal ini dilakukan untuk memastikan bahwa kedua model mengukur data yang sama dengan tujuan keterbandingan model. Model konvensional yang digunakan adalah model univariat sederhana berupa autoregressive dengan ordo 2 atau $A R(2)$.

\section{Data dan Sumber Data}

Periode data yang digunakan dimulai dari 2012Q2-2020Q4 atau dimulai dari bulan April 2012. Periode data dipilih dengan mempertimbangkan ketersediaan data dan upaya untuk mengevaluasi model yang mengikutsertakan guncangan ekonomi pada masa pandemi COVID-19. Ruang lingkup penelitian terdiri atas tujuh provinsi di Indonesia, yaitu Sumatera Utara (SU), Riau (RI), Lampung (LA), Banten (BA), Jawa Tengah (JT), Jawa Timur (JT), dan Bali (BA). Pemilihan tujuh provinsi didasarkan atas ketersediaan data Google Trends dan rentang data yang digunakan. Data pertumbuhan PDRB triwulanan diperoleh dari situs web Badan Pusat Statistik (BPS). Data Google Trends diperoleh dengan cara scraping data menggunakan package gTrendsR pada aplikasi R Studio. Frekuensi data Google Trends yang digunakan adalah bulanan dimana hal ini dapat diperoleh ketika pengguna meminta data pada rentang lebih dari lima tahun.

Data Google Trends merupakan sebuah indeks berbentuk rasio pencarian. Woloszko (2020) menyatakan rasio pencarian dengan rumus berikut:

$$
S V I_{c t}=\frac{S V_{c t}}{S V T_{t}} * C_{c}
$$

Rasio berupa Search Volume Indices (SVI) tersebut merupakan perbandingan dari volume pencarian dari suatu kategori atau topik pada waktu tertentu berupa Search Volume (SV) terhadap total dari seluruh volume pencarian berupa Search Volume Total (SVT). Indeks $c$ menyatakan kategori atau topik dan $t$ menyatakan waktu. Rasio tersebut dikalikan dengan konstanta $C_{c}=\left(\max _{t} \frac{S V_{c t}}{S V T_{t}}\right)^{-1}$ untuk memastikan bahwa indeks SVI memiliki nilai maksimum 100. Rasio Google Trends memiliki rentang 0-100 dimana 0 menyatakan bahwa pencarian sangat sedikit dan 100 menyatakan bahwa pencarian paling populer di waktu dan tempat tersebut. Indeks bernilai 0 yang dihasilkan dapat menyebabkan data menjadi ambigu karena dapat mengartikan bahwa tidak ada pencarian yang dilakukan pada saat itu. Hal ini merupakan keterbatasan data Google Trends dan menyebabkan ruang lingkup penelitian ini menjadi lebih sedikit. Telah disebutkan bahwa rentang data yang digunakan dimulai dari triwulan kedua 2012 atau bulan April 2012 dimana terdapat berbagai provinsi yang memiliki indeks pencarian 0 sampai tahun 2013. Hal ini terjadi akibat adanya proses pengembangan pengumpulan data Google Trends di berbagai daerah sehingga pencarian pada suatu subkategori tidak tercakup dan menghasilkan nilai SVI nol pada beberapa tahun (Woloszko, 2020).

Data Google Trends dapat menangkap banyaknya pencarian dari suatu kata kunci, topik, dan kategori. Penelitian ini menggunakan topik dan kategori untuk menghindari permasalahan perbedaan bahasa dan mencakup berbagai kata kunci dari suatu aktivitas ekonomi. Woloszko (2020) menyatakan bahwa penggunaan topik dan kategori dapat mencakup banyaknya sektor ekonomi. Topik dan kategori dari Google Trends dikonkordansikan terhadap subsektor PDRB menurut pendekatan produksi. Untuk dapat menggabungkan subsektor menjadi sektor, digunakan komponen utama pertama. Berikut konkordansi yang dilakukan:

Tabel 1. Konkordansi topik dan kategori Google Trends terhadap subsektor PDRB menurut pendekatan produksi

Sektor PDRB Kategori Google

(1)

(2)

\begin{tabular}{ll}
\hline A.PERTANIAN, PETERNAKAN, KEHUTANAN, PERIKANAN & \\
Tanaman Bahan Makanan & Food Production \\
Tanaman Perkebunan & Agriculture \\
$\begin{array}{l}\text { Peternakan dan Hasil-hasilnya } \\
\text { Kehutanan }\end{array}$ & $\begin{array}{l}\text { Animal Product \& Services } \\
\text { B.PERTAMBANGAN DAN PENGGALIAN }\end{array}$ \\
Minyak dan Gas Bumi & \\
$\begin{array}{l}\text { Pertambangan Bukan Migas } \\
\text { C. INDUSTRI PENGOLAHAN }\end{array}$ & Oil \& Gas \\
Makanan, Minuman, \& Tembakau & Metals \& Mining \\
Tekstil, Barang Kulit \& Alas Kaki & \\
\end{tabular}




\begin{tabular}{ll}
\hline Barang Kayu \& Hasil Hutan Lainnya & Wood \\
Kertas dan Barang Cetakan & Paper \\
Pupuk, Kimia \& Barang dari Karet & Chemical Industry \\
Semen \& Barang Galian bukan Logam & Cement \\
Alat Angkutan, Mesin \& Peralatannya & Automotive Industry \\
D.LISTRIK, GAS DAN AIR BERSIH & \\
Listrik & Electricity \\
Gas Kota & Gasoline \\
Air Bersih & Water Filters \& Purifiers \\
E. KONSTRUKSI & \\
F.PERDAGANGAN, HOTEL DAN RESTORAN & \\
Perdagangan Besar dan Eceran & Retail Trade \\
Hotel & Hotel \& Accommodation \\
Restoran & Restaurants \\
G.PENGANGKUTAN DAN KOMUNIKASI & \\
Angkutan Rel & Rail Transportation \\
Angkutan Jalan Raya & Urban Transportation \\
Angkutan Laut & Maritime Transportation \\
Angkutan Udara & Aviation, Airport Parking \& \\
Komunikasi & Internet \& Telecom \\
H.KEUANGAN, REAL ESTAT \& JASA PERUSAHAAN & \\
Bank & Banking \\
Lembaga Keuangan Bukan Bank & Financial Markets \\
Jasa Penunjang Keuangan & Business Finance \\
Real Estate & Real Estate \\
Jasa Perusahaan & Business Service \\
I.JASA - JASA & \\
Adm. Pemerintahan \& Pertahanan & State \& Local Government \\
Jasa Pemerintahan Lainnya & Government Contracting \& Procurement \\
Sosial Kemasyarakatan & Social Services \\
Hiburan dan Rekreasi & Entertainment \& Industry \\
Perorangan dan Rumah Tangga & Housing \& Development \\
\hline
\end{tabular}

Sembilan sektor hasil konkordansi tersebut digunakan sebagai variabel bulanan untuk nowcasting pertumbuhan PDRB triwulanan. Variabel bulanan tersebut ditransformasi dalam bentuk pertumbuhan year on year untuk menghilangkan efek musiman dari frekuensi bulanan sekaligus pemenuhan kondisi data stasioner. Berikut persamaan transformasi yang dilakukan terhadap variabel Google Trends:

$$
\frac{X_{t}-X_{t-12}}{X_{t-12}}
$$

Pertumbuhan PDRB triwulanan juga ditransformasi dalam bentuk beda berikut: $\left(Y_{t}-Y_{t-4}\right)-$ $\left(Y_{t-1}-Y_{t-5}\right)$. Agar hasil nowcasting dapat diinterpretasikan, diperlukan pengembalian transformasi setelah membentuk pemodelan nowcasting dengan persamaan berikut:

$$
Y_{t}=\Delta\left(\Delta Y_{t, 4}\right)+Y_{t-4}+Y_{t-1}-Y_{t-5}
$$

\section{HASIL DAN PEMBAHASAN}

\section{Hasil Pengujian Stasioneritas}

Sebelum melakukan nowcasting, dilakukan pengujian stasioneritas terhadap variabel hasil transformasi. Nilai statistik uji t dibandingkan dengan nilai kritis dari Mackinon dimana apabila nilai statistik uji $\mathrm{t}$ kurang dari nilai kritis Mackinon, maka hasil pengujian berada pada wilayah tolak. Nilai kritis Mackinon adalah 1,944 untuk $\alpha=5 \%$, sehingga hasil pengujian pada Tabel 2 menunjukkan bahwa seluruh variabel hasil 
transformasi memenuhi kondisi stasioneritas karena seluruh nilai statistik uji berada pada wilayah tolak. Berdasarkan hasil pengujian tersebut, maka seluruh variabel dapat digunakan untuk pemodelan nowcasting.

Tabel 2. Hasil pengujian stasioneritas menggunakan uji augmented Dickey-Fuller

\begin{tabular}{ccccccccc}
\hline Sektor & Keterangan & SU & RI & LA & JT & BT & BA & JI \\
\hline \multirow{2}{*}{$\mathrm{A}$} & $t$-Stat & -13.0831 & -9.3729 & -9.8972 & -9.9308 & -10.0762 & -10.5081 & -10.3771 \\
& pvalue & 0.01 & 0.01 & 0.01 & 0.01 & 0.01 & 0.01 & 0.01 \\
& $t$-Stat & -12.3006 & -6.6268 & -5.5237 & -10.0107 & -10.7544 & -8.3739 & -6.7305 \\
$\mathrm{~B}$ & pvalue & 0.01 & 0.01 & 0.01 & 0.01 & 0.01 & 0.01 & 0.01 \\
& $t$-Stat & -6.8420 & -10.4028 & -11.5121 & -7.4857 & -7.5119 & -9.0386 & -10.3861 \\
$\mathrm{C}$ & -value & 0.01 & 0.01 & 0.01 & 0.01 & 0.01 & 0.01 & 0.01 \\
& $t$-Stat & -10.2141 & -10.3271 & -10.5210 & -9.0855 & -10.2834 & -8.5887 & -7.7729 \\
$\mathrm{D}$ & pvalue & 0.01 & 0.01 & 0.01 & 0.01 & 0.01 & 0.01 & 0.01 \\
& $t$-Stat & -8.4388 & -10.2343 & -10.1261 & -12.9194 & -9.1669 & -10.0449 & -6.4334 \\
$\mathrm{E}$ & pvalue & 0.01 & 0.01 & 0.01 & 0.01 & 0.01 & 0.01 & 0.01 \\
& $t$-Stat & -7.5344 & -10.5258 & -10.1314 & -9.3404 & -5.6625 & -8.9978 & -9.0095 \\
$\mathrm{~F}$ & pvalue & 0.01 & 0.01 & 0.01 & 0.01 & 0.01 & 0.01 & 0.01 \\
& $t$-Stat & -10.7335 & -9.3334 & -15.0683 & -11.1978 & -10.7201 & -9.6070 & -7.7575 \\
$\mathrm{G}$ & vvalue & 0.01 & 0.01 & 0.01 & 0.01 & 0.01 & 0.01 & 0.01 \\
& $t$-Stat & -12.8963 & -7.1831 & -7.1573 & -10.6016 & -10.0772 & -10.8754 & -7.2853 \\
$\mathrm{H}$ & pvalue & 0.01 & 0.01 & 0.01 & 0.01 & 0.01 & 0.01 & 0.01 \\
& $t$-Stat & -9.6406 & -7.9788 & -10.3415 & -8.5619 & -10.3323 & -9.2589 & -11.2613 \\
$\mathrm{I}$ & pvalue & 0.01 & 0.01 & 0.01 & 0.01 & 0.01 & 0.01 & 0.01 \\
\hline
\end{tabular}

\section{Nowcasting Pertumbuhan Ekonomi Regional}

Hasil nowcasting menggunakan DFM ditunjukkan pada Gambar 3 menggunakan plot berwarna biru. Secara umum, hasil nowcasting pada periode yang mendekati periode berjalan semakin mendekati nilai pertumbuhan PDRB. Hal ini terlihat melalui plot berwarna biru dan hitam yang berhimpitan. Hasil nowcasting tersebut juga menunjukkan bahwa penurunan ekonomi pada masa pandemi COVID-19 dapat ditangkap dengan baik. Hal ini dapat dilihat melalui hasil peramalan pada triwulan pertama 2020 yang turut menurun tajam mengikuti pertumbuhan ekonomi yang terkontraksi.

Penurunan pertumbuhan ekonomi terendah pada triwulan berjalan atau 2020Q4 dialami oleh Provinsi bali pada nilai $-12,21 \%$. Besar pertumbuhan PDRB tersebut dapat ditangkap dengan baik melalui DFM yang menghasilkan besaran nowcasting sebesar $-12,41 \%$. Hal ini menunjukkan bahwa pada provinsi dengan penurunan yang sangat tajam, hasil nowcasting masih dapat menangkap besaran yang mendekati nilai sebenarnya. Apabila pengamatan dimulai sejak masa pandemi COVID-19, dapat diketahui bahwa hasil nowcasting sudah memiliki arah yang sama dengan pertumbuhan PDRB di Bali. Hal ini dapat dilihat berupa pertumbuhan ekonomi pada 2020Q1-2020Q3 yang terus menurun dan 2020Q4 yang mulai mengalami ekspansi.

Secara visual, hasil nowcasting yang menunjukkan nilai yang berfluktuasi dan tidak berimpit dengan plot pertumbuhan PDRB adalah Provinsi Riau. Dapat diamati bahwa besaran yang dihasilkan pada beberapa periode perlu perhatian, seperti pada 2013Q4 yang mengalami underestimated dan 2017Q1 yang mengalami overestimated. Selain itu, hasil nowcasting menunjukkan pola yang mengalami delay atau keterlambatan satu periode. Dalam arti, hasil nowcasting pada periode berjalan lebih baik untuk menunjukkan kondisi periode sebelumnya. Hal ini menimbulkan kelemahan dalam hasil nowcasting karena tidak mampu menggambarkan kondisi yang sedang berjalan. Meskipun begitu, pola yang sudah diketahui di Provinsi Riau dapat memberikan pemahaman mengenai pola yang terjadi di masa mendatang.

\section{Evaluasi Kinerja Model Nowcasting}

Evaluasi kinerja model dilakukan dengan perbandingan antar periode dan antar model. Nilai relatif terhadap AR(2) menunjukkan rasio RMSE DFM terhadap RMSE AR(2). Apabila nilai relatif kurang dari satu, maka dapat disimpulkan bahwa kinerja peramalan DFM lebih baik daripada model konvensional. RMSE AR(2) diperoleh dari peramalan berdasarkan data historis pertumbuhan PDRB y-on-y. Perbandingan antar periode dilakukan dengan melihat RMSE pada rentang data hingga 2019Q4 dan rentang data hingga 2020Q4.Akurasi model nowcasting ditunjukkan pada tabel berikut: 
Tabel 3. RMSE DFM, AR(2), dan DFM relatif terhadap AR(2) pada masa sebelum dan masa pandemi COVID-19

\begin{tabular}{ccccccc}
\hline \multirow{2}{*}{ Provinsi } & \multicolumn{3}{c}{$2019 \mathrm{Q} 4$} & \multicolumn{3}{c}{$2020 \mathrm{Q} 4$} \\
\cline { 2 - 6 } & AR(2) & DFM & $\begin{array}{c}\text { Relatif } \\
\text { terhadap } \\
\text { AR(2) }\end{array}$ & AR(2) & DFM & $\begin{array}{c}\text { Relatif } \\
\text { terhadap } \\
\text { AR(2) }\end{array}$ \\
\hline SU & 0.4545 & 0.1339 & 0.3517 & 1.2599 & 1.0688 & 0.8484 \\
RI & 2.7956 & 4.7698 & 2.0181 & 2.8361 & 5.135 & 1.8106 \\
LA & 1.2916 & 1.3311 & 1.2821 & 1.7145 & 1.7085 & 0.9965 \\
JT & 1.2577 & 1.2496 & 1.2101 & 2.0329 & 3.2775 & 1.6122 \\
BT & 1.4237 & 0.5517 & 0.4763 & 2.2986 & 2.1523 & 0.9364 \\
BA & 1.3052 & 0.1957 & 0.165 & 2.255 & 2.071 & 0.9184 \\
JI & 0.5317 & 1.0699 & 2.6991 & 1.7111 & 2.8971 & 1.6931 \\
\hline
\end{tabular}

Evaluasi model dengan membandingkan antar periode menunjukkan bahwa peramalan pada masa sebelum pandemi COVID-19 menunjukkan RMSE lebih kecil di seluruh provinsi. Kondisi tersebut diamati berdasarkan nilai RMSE pada data hingga 2019Q4 yang lebih kecil daripada data hingga 2020Q4. Hal ini berarti bahwa DFM dapat melakukan peramalan lebih baik tanpa adanya guncangan ekonomi yang terjadi. Hasil tersebut dinilai wajar terjadi pada metode peramalan yang tidak memberi perlakuan khusus pada non linearitas data, namun terjadi suatu pola yang mengalami peningkatan atau penurunan tajam. Penelitian oleh Woloszko (2020) juga menunjukkan hasil peramalan yang serupa dimana periode sampel dengan memasukkan guncangan ekonomi akibat krisis ekonomi global pada tahun 2008 menunjukkan hasil peramalan yang lebih buruk. Hasil tersebut menunjukkan bahwa pada kondisi ekonomi yang cukup stabil, data Google trends dapat dipertimbangkan dengan baik untuk digunakan dalam melihat gambaran arah pergerakan ekonomi.

Evaluasi model dengan membandingkan antar metode menunjukkan bahwa DFM bekerja lebih baik dibandingkan model univariat di Provinsi Sumatera Utara, Lampung, Banten, dan Bali untuk nowcasting 2020Q4. Meskipun terdapat provinsi yang tidak mengungguli metode AR(2), namun provinsi lainnya menghasilkan RMSE yang tidak berbeda jauh dibandingkan provinsi lainnya, kecuali di Provinsi Riau.

Nilai RMSE menggunakan DFM yang besar di Riau sejalan dengan kurva peramalan sebelumnya dimana terjadi keterlambatan hasil nowcasting. Hal ini yang menyebabkan besarnya nilai RMSE di Riau. Provinsi Riau mengalami beberapa kontraksi dan eskpansi yang perlu diperhatikan pula. Pada triwulan kedua 2015, terjadi kontraksi pertumbuhan ekonomi sebesar 2,06\% dimana penurunan tersebut bersumber dari penurunan kinerja sektor pertambangan penggalian, pertanian, kehutanan, perikanan, penurunan ekspor dan perlambatan investasi (Bank Indonesia, 2015). Sebelum tahun 2015, penurunan kinerja ekonomi terjadi pula pada triwulan keempat 2012. Pada periode tersebut, sumber penurunan pertumbuhan ekonomi adalah konsumsi. Hal ini erat kaitannya dengan turunnya harga CPO dunia yang mengakibatkan penurunan harga jual Tandan Buah Segar (TBS) Riau. Penurunan harga kelapa sawit menyebabkan pelemahan tingkat keyakinan konsumen (Bank Indonesia, 2012). Berdasarkan sumber penurunan ekonomi tersebut, dapat diketahui bahwa Provinsi Riau didominasi oleh sektor primer. Hal ini menunjukkan bahwa pencarian terhadap sektor primer yang ditangkap melalui data Google Trends belum cukup baik dalam menjelaskan sektor primer secara riil. 


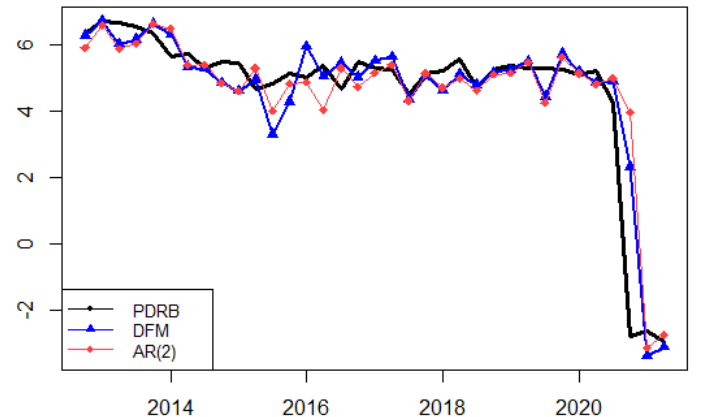

A. Sumatera Utara

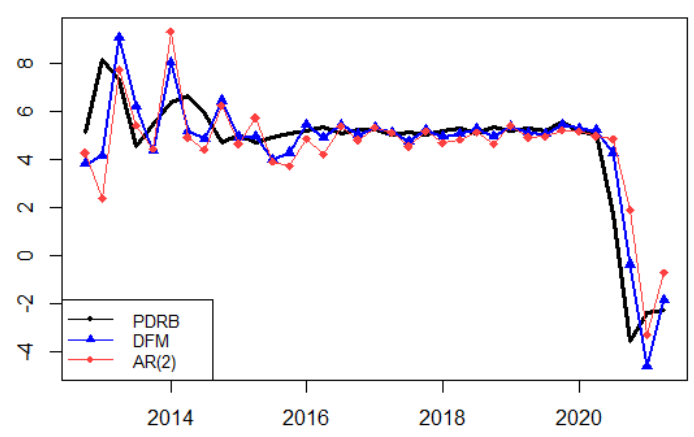

C. Lampung

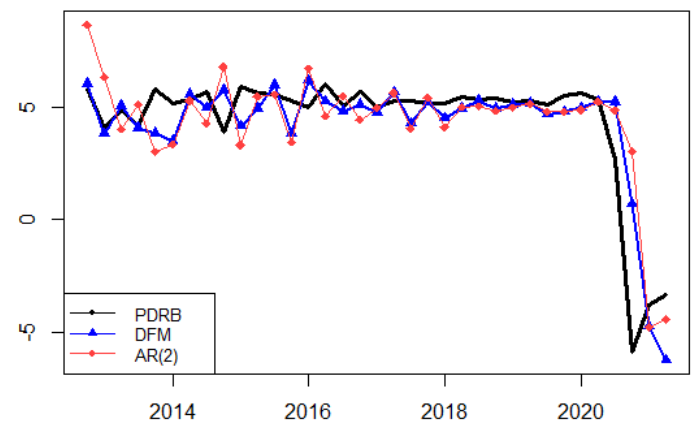

E. Jawa Tengah

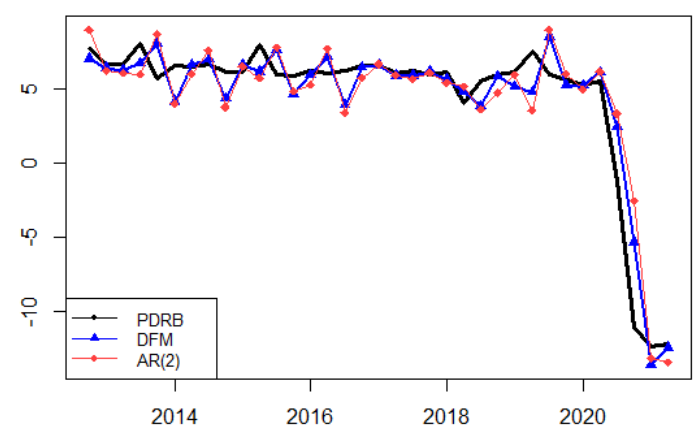

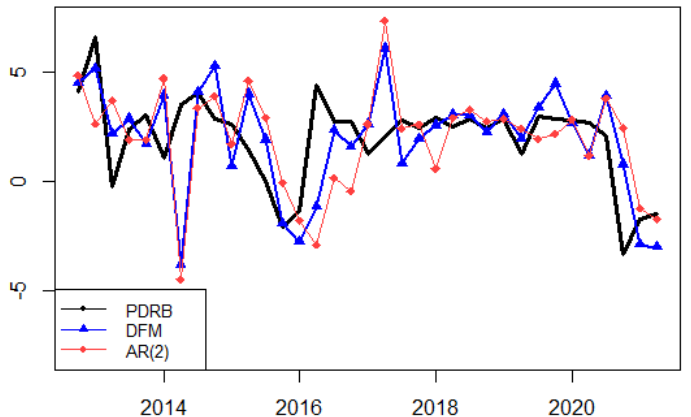

B. Riau

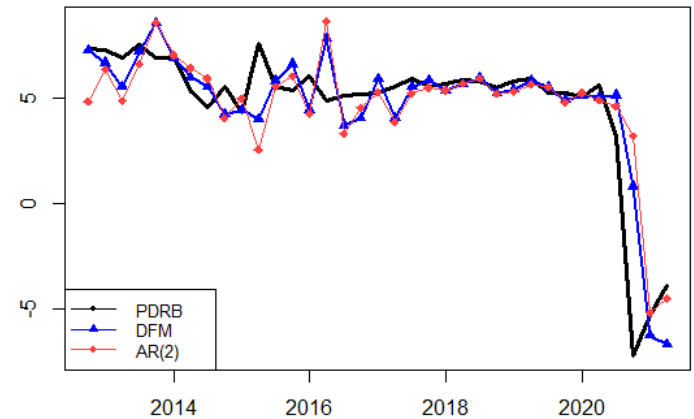

D. Banten

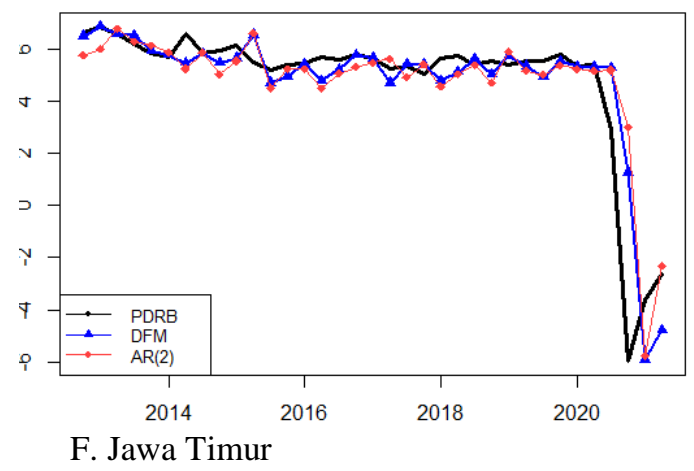

G. Bali

Gambar 2. Pertumbuhan PDRB triwulanan dan hasil nowcasting DFM 
Giannone, Reichlin, \& Small (2008) menyatakan bahwa residual DFM diasumsikan bersifat white noise. Gujarati (2004) menyebutkan bahwa residual yang bersifat white noise memiliki rata-rata nol, varians konstan, dan tidak berautokorelasi. Pengujian dilakukan menggunakan uji augmented Dickey-Fuller (ADF) karena pengujian unit-root dapat menunjukkan bahwa data stasioner. Residual yang memenuhi kondisi stasioneritas telah memenuhi pula kondisi white noise. Tabel 4 menunjukkan hasil pengujian terhadap residual dimana.diperoleh hasil bahwa seluruh model memenuhi kondisi white noise.

Tabel 4. Hasil pengujian white noise DFM

\begin{tabular}{ccccc}
\hline \multirow{2}{*}{ Provinsi } & \multicolumn{2}{c}{$2019 \mathrm{Q} 4$} & \multicolumn{2}{c}{ 2020Q4 } \\
\cline { 2 - 5 } & Statistik & $p$-value & Statistik & $p$-value \\
\hline SU & -6.1859 & 0.01 & -6.2133 & 0.01 \\
RI & -5.9486 & 0.01 & -6.4598 & 0.01 \\
LA & -6.2876 & 0.01 & -6.0108 & 0.01 \\
BT & -7.1830 & 0.01 & -5.4060 & 0.01 \\
JT & -6.8009 & 0.01 & -6.1365 & 0.01 \\
JI & -6.8003 & 0.01 & -6.6142 & 0.01 \\
BA & -6.6241 & 0.01 & -5.5662 & 0.01 \\
\hline
\end{tabular}

\section{KESIMPULAN}

Berdasarkan hasil dan pembahasan, diperoleh kesimpulan bahwa nowcasting pada level provinsi dapat dilakukan dengan memanfaatkan data Google Trends dimana data dapat diperoleh secara cepat dan mampu menunjukkan aktivitas ekonomi melalui konkordansi yang dilakukan terhadap subsektor PDRB menurut pendekatan produksi. Akurasi model nowcasting menunjukkan bahwa model bekerja lebih baik pada masa sebelum pandemi COVID-19 sehingga data Google Trends dapat dipertimbangkan dengan baik untuk digunakan pada masa ekonomi yang stabil. Apabila dibandingkan terhadap model univariat, masih terdapat nilai relatif yang lebih dari satu. Hasil peramalan di Provinsi Riau menggunakan data Google Trends memerlukan perhatian khusus dimana hasil menunjukkan RMSE yang tinggi dan besaran nowcasting yang mengalami keterlambatan.

\section{DAFTAR PUSTAKA}

Bańbura, M., Giannone, D., \& Reichlin, L. (2010). Nowcasting. ECB Working Paper No. 1275.

Bank Indonesia. (2012). Kajian Ekonomi dan Keuangan Regional Triwulan IV 2012 Provinsi Riau.

Bank Indonesia. (2015). Kajian Ekonomi dan Keuangan Regional Triwulan II 2015 Provinsi Riau.

Chernis, T., Cheung, C., \& Velasco, G. (2017). A three-frequency dynamic factor model for nowcasting Canadian provincial GDP growth. International Journal of Forecasting, 36(3), 851-872.

Clayton-Matthews, A., \& Stock, J. H. (1999). An application of the Stock/Watson index methodology to the Massachusetts economy. Journal of Economic and Social Measurement, 25, 183-233.

de Valk, S., de Mattos, D., \& Ferreira, P. (2019). Nowcasting: An R package for predicting economic variables using dynamic factor models. $R$ Journal, $11(1), 1-15$.

Giannone, D., Reichlin, L., \& Small, D. (2008). Nowcasting: The real-time informational content of macroeconomic data. Journal of Monetary Economics, 55, 665-676.

Gujarati, D. N. (2004). Basic Econometrics. Tata McGraw-Hill.

Hamilton, J. D. (1994). Time series analysis. Princeton University Press.

Heikkinen, J. (2019). Nowcasting GDP growth using Google Trends. Jyväskylä University.

Ineichen, A. (2015). Nowcasting: A Risk Management Tool. Alternative Investment Analyst Review, Summer, 45-50.

Luciani, M., Pundit, M., Ramayandi, A., \& Veronese, G. (2018). Nowcasting Indonesia. Empirical Economics, 55(2), 597-619.

Mariano, R. S., \& Murasawa, Y. (2003). A new coincident index of business cycles based on monthly and quarterly series. Journal of Applied Econometrics, 18(4), 427-443.

Tarsidin, Idham, \& Rakhman, R. N. (2018). Nowcasting Household Consumption and Investment in Indonesia. Bulletin of Monetary Economics and Banking, 20(3), 375-404.

Woloszko, N. (2020). Tracking activity in real time with Google Trends. OECD Economics Departmen Working Papers, 1634. 